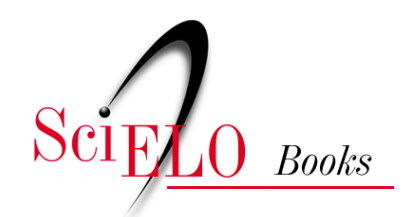

\title{
A imigração senegalesa dimensões históricas, econômicas e socioambientais
}

\author{
João Carlos Tedesco
}

\section{SciELO Books / SciELO Livros / SciELO Libros}

TEDESCO, J.C. A imigração senegalesa: dimensões históricas, econômicas e socioambientais. In: GERHARDT, M., NODARI, E.S., and MORETTO, S.P., eds. História ambiental e migrações: diálogos [online]. São Leopoldo: Oikos; editora UFFS, 2017, pp. 237-257. ISBN: 978-85-64905-68-9. https://doi.org/10.7476/9788564905689.0015.

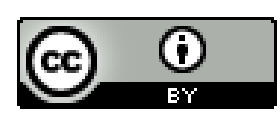

All the contents of this work, except where otherwise noted, is licensed under a Creative Commons Attribution 4.0 International license.

Todo o conteúdo deste trabalho, exceto quando houver ressalva, é publicado sob a licença Creative Commons Atribição 4.0.

Todo el contenido de esta obra, excepto donde se indique lo contrario, está bajo licencia de la licencia $\underline{\text { Creative Commons }}$ Reconocimento 4.0. 


\section{A imigração senegalesa: dimensões históricas, econômicas e socioambientais}

João Carlos Tedesco

\section{Introdução}

O Senegal é um país da África Ocidental (extremo oeste) e subsaariana; possui um território equivalente ao do estado do Rio Grande do Sul, com população em torno de 14 milhões, sendo a população feminina superior $(50,90 \%)$ em relação à masculina $(49,10 \%)$, tendo as cidades de Dakar (capital), Thiès, Diourbel, Kaolack, Saint-Louis, Dagana e Ziguinchor como as mais populosas (MALOMANO; FONSECA; BADI, 2015). É um país de grande maioria islâmica, tendo as confrarias Muride, Tijane e Qadirya como as de maior quantidade de adeptos, em particular a primeira e com grande correlação com a dinâmica migratória. A nação conquistou sua independência em relação à França em 1960, sob o comando político de Léopold Senghor.

A imigração senegalesa para a América do Sul, em particular para o centro-sul do Brasil e a região metropolitana de Buenos Aires (Argentina), vem chamando a atenção de pesquisadores, bem como de outros horizontes, principalmente sociais, políticos e religiosos (TEDESCO; MELLO, 2015; KLEIDERMACHER, 2015). É uma imigração que expressa a nova tendência dos fluxos mundiais na direção Sul-Sul, ou seja, de países empobrecidos para os considerados em vias de desenvolvimento.

Para entender os processos que determinam as direções de destino, faz-se necessário também compreender os elementos históricos e conjunturais que produzem as saídas. Nesse sentido, o caso específico do Senegal é paradigmático, pois é um país considerado democrático, sem maiores conflitos bélicos, guerra civil, tensões religiosas e de limites de fronteiras nacionais, realidade essa que dificulta a obtenção do visto que os identifica como refugiados. Desse modo, as causas do fenômeno emigratório devem ser buscadas em outros horizontes. 
Figura 1: Mapa da África com indicação para o Senegal

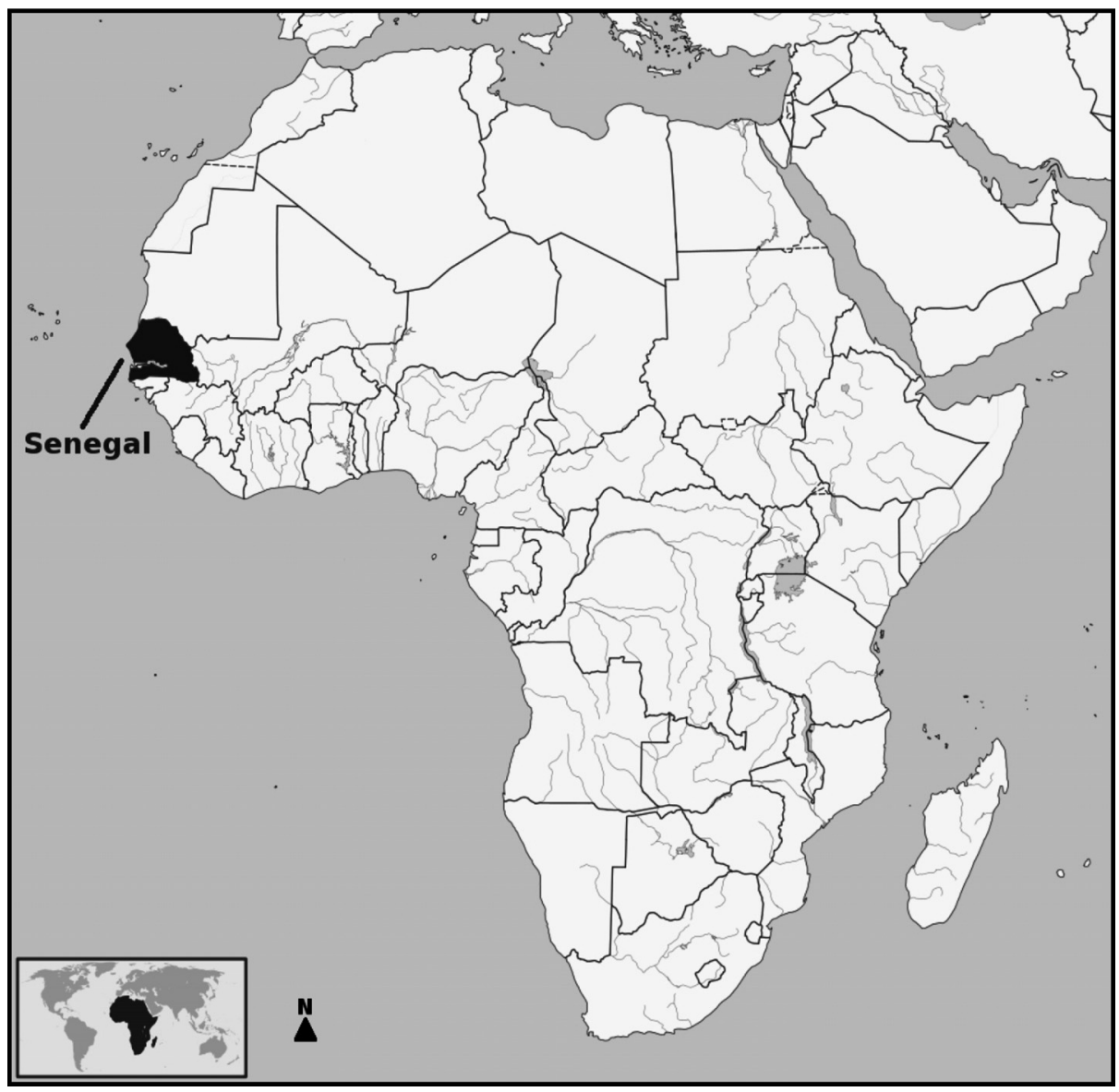

Fonte: Adaptado de Wikimedia Commons. Disponível em: <https://upload.wikimedia.org/ wikipedia/commons/thumb/f/ff/Senegal_in_Africa.svg/1084pxSenegal_in_Africa.svg.png>. Acesso em: 21 abr. 2017.

É com essa intenção que propomos dar uma contribuição no sintético texto. Buscamos analisar alguns elementos que dão a dimensão histórica da atual diáspora senegalesa para o mundo. ${ }^{1}$ Fizemos um recorte tempo-

\footnotetext{
${ }^{1}$ Os últimos dados atestam a cifra de mais de 3 milhões em 2016. A grande maioria se encontra na Europa Ocidental, em particular, na França (país colonizador), Itália, Espanha e Inglaterra (CEPED, 2017, p. 11).
} 
ral a partir das primeiras décadas do século XX em razão das duas Guerras Mundiais e a dinâmica de pressão migratória que o país enfrentou sob o regime colonial nesse período, pois há uma estreita ligação com a emigração; correlacionamos alguns períodos de maior expressão de saída com as dinâmicas de desenvolvimento e centralidade no meio rural e na produção agrícola de algumas regiões do país, em particular, o Bassin Arachidier, espaço de grande produção do amendoim, o qual tornou-se o carro-chefe de um processo de modernização produtiva iniciada nos anos 60 e intensificada na década de 1970 e que produziu um amplo espectro do fenômeno (e)migratório. Nesse sentido, entendemos que não é possível compreender a trajetória histórica da emigração senegalesa sem ter presente esses processos sociais, econômicos e ambientais que, interligados com fenômenos de ordem cultural, familiar e religiosa, deram o tom dessa realidade.

O que queremos demonstrar é que nesse cenário das emigrações laborais, as quais caracterizam a grande emigração senegalesa, as causalidades podem ser múltiplas e correlacionais, tendo processos estruturais e subjetivos, ambos de difícil determinação e hierarquia (WIHTOL DE WENDEN, 2005), como importantes. Desse modo, meio ambiente, políticas de tendências produtivistas no meio rural, saberes tradicionais, redefinições sociais de unidades familiares, horizontes religiosos imbricam-se e produzem realidades migratórias.

\section{Elementos da economia colonial do Senegal no período após a Primeira Guerra}

A Primeira Guerra Mundial inaugura um novo período da história do Senegal. Durante a referida guerra e no período entre as duas grandes guerras, ocorreu, ao mesmo tempo, o auge da capacidade de atuação das instituições imperialistas principalmente francesas, e as colônias foram integradas ao sistema do capitalismo europeu ocidental (COQUERY-VIDROVITCH, 2010). A orientação da economia estava organizada principalmente pela extração de produtos agrícolas, pautada pela necessidade econômica da metrópole. ${ }^{2}$

\footnotetext{
${ }^{2}$ Uma análise mais detalhada e de um período mais longo correlacionando dinâmica econômica e política com emigração do Senegal, encontra-se em Tedesco; Mello (2015). Parte do que desenvolvemos nesse item, encontra-se no referido livro.
} 
No fim da Segunda Guerra Mundial, a economia do Senegal continuava sendo majoritariamente agrícola, o que a tornava pouco atrativa para investimentos estruturais, principalmente no campo industrial, sendo a opção mais rentável a alocação da produção em uma economia de mercado, conhecido como économie de traire, que consistia no direcionamento da maior parte da produção disponível para ao mercado externo, produção viabilizada pelos métodos tradicionais, fechando o ciclo com a importação de bens de consumo e sistematizando uma rede de dependência da colônia em relação à metrópole. Devido à dependência econômica, a balança comercial apresentava-se em uma posição deficitária aos africanos. É nesse período que a economia do Senegal ganha performance de atrelamento a um sistema produtivo de estreita vinculação à economia mundial, principalmente da cultura do amendoim, da castanha e da criação de gado (COQUERY-VIDROVITCH, 2010).

Em razão da Segunda Guerra, o país foi obrigado a produzir alimentos, mas principalmente o algodão, forçando ainda mais a inserção da população em uma economia de mercado, de produção de culturas exportáveis. As populações eram obrigadas a reverter a baixa dos preços com o aumento da produção (TALL, 2009). A rentabilidade da agricultura teve uma queda vertiginosa, além do que provocou alterações no sistema tradicional de produzir das unidades familiares no meio rural. Foi dada prioridade ao amendoim e ao algodão em detrimento de outras culturais tradicionais dos camponeses.

O esforço de guerra, que orientou a institucionalização de artigos de produção obrigatória, foi especialmente dramático para os africanos. Ao fim da guerra, porém, a França cessou sua compra drasticamente, impactando uma organização construída para esse fim, não preparada para a perda de demanda. Além de desorganizar ainda mais os mecanismos produtivos, a obrigatoriedade da produção e da venda para a França acabou por impossibilitar a produção para o abastecimento interno. Ao fim da guerra, os campos estavam esgotados e as reservas desfalcadas por períodos de estiagem. Isso tudo produziu um grande colapso produtivo, bem como uma crise de alimentos que se alastrou por toda a região, vitimando entre $250 \mathrm{a}$ 400 mil pessoas (COQUERY-VIDROVITCH, 2010).

O período posterior à Segunda Guerra foi apenas o de maior expressão da fome; o sistema de économie de traite tornou a falta de alimentos uma constante do período colonial. O país ficou completamente vulnerável às estiagens que se estendiam e se intensificavam por toda a década de 1950, 
fazendo com que grande parte da população passasse a procurar os centros urbanos. As epidemias só não foram mais alarmantes devido à operação de sistemas de transporte que auxiliavam no manejo de alimentos para locais mais debilitados. As epidemias foram controladas por campanhas sanitárias iniciadas no período. Porém, essas medidas levavam ao aumento das despesas sociais, que precisavam ser pagas pela população.

No final dos anos 50 e por toda a década de 1960, a migração interna foi muito intensa, inclusive a externa, principalmente em países vizinhos como o Mali e a Guiné Bissau, como estratégia para fazer frente aos limites do processo produtivo rural e o reduzido emprego urbano, em particular, de Dakar. Junto com esse fenômeno migratório interno e externo, um contigente intenso emigrou para a França para fazer parte das fileiras militares, bem como para atuar em setores estratégicos de guerra e do pós-guerra, como é o caso de mineração, pesca, construção civil, agricultura e metalurgia. Para a França, a emigração dos anos 50 tinham também o objetivo de reconstruir as metrópoles destruídas pela Segunda Guerra e construir estradas. Entre os anos de 1950 e 60, núcleos de senegaleses se constituíam em várias regiões industriais da França (POIRET, 1996). Na África, senegaleses emigravam também para colônias francesas em outros países vizinhos da parte oeste e ocidental atuando em setores de comércio, navegação, pesca e agricultura (BADIER, 2008).

\section{A imigração e o nacionalismo no ocidente africano}

A questão do nacionalismo no Senegal faz parte de um conjunto de processos relacionados à própria dinâmica das imposições e dos desdobramentos do imperialismo francês exercido durante o período das duas guerras. Da mesma forma que a instituição do sistema colonial se cristaliza, a partir do período da Primeira Guerra Mundial, o movimento nacionalista passa a ser delineado e a representar a própria transformação cultural imposta aos africanos.

Muitos membros da elite tradicional procuraram cooperar com a sua metrópole, visando receber retribuições políticas devido a sua participação no esforço de guerra. Muitos enviaram voluntariamente recursos financeiros, além de manterem a fidelidade à potência colonial e, asseguraram, desta forma, a supressão de revoltas. Contudo, com o fim da guerra, as retribuições desejadas, como uma maior autonomia, que foi propagada pelo discurso do presidente norte-americano Woodrow Wilson por meio dos princípios de 
autodeterminação dos povos e de democracia liberal, foram ignoradas pela metrópole. Aliado a isso, a guerra teve um efeito psicológico importante: demonstrou que o homem branco também morria frente aos armamentos modernos e invalidou as justificativas legitimadamente científicas da superioridade racial. Esse conjunto de frustrações e novas percepções tornou os africanos mais propensos a participar de movimentos anticoloniais.

A legislação política sempre buscava suprimir a nova elite educada e os profissionais liberais, porém, com a maior integração cultural, houve o aumento do fluxo de formação desses grupos; também aumentou o número de africanos que iam estudar em escolas do exterior. As áreas urbanas iam congregando grupos que desejavam maior participação e a expansão da agricultura de exportação. Esse processo fez com que o poder econômico dos chefes tradicionais fosse, pelo menos em parte, superado por um contingente de jovens que ficavam mais ricos que os chefes, que passaram a ressentir-se pela falta de legitimidade da detenção de poderes não ligados aos compromissos tradicionais.

A luta contra o colonialismo e, sobretudo, a "tomada de consciência dos negros do mundo inteiro sobre sua condição de vítimas da opressão e da tirania" (BOAHEN, 2010, p. 729), fomentou a arregimentação de novos membros na causa nacionalista, sobretudo na África Ocidental. O Senegal, como centro mais próximo à metrópole, foi um dos principais locais de desenvolvimento de ações políticas devido ao seu relacionamento mais antigo com a França e de ter sido o centro da expansão colonial.

A presença do Islamismo no Senegal sempre se caracterizou como um fenômeno de resistência, sendo fomentador de unidade social e política. Foi um fator importante como motivador de transformações, principalmente nos períodos de crise política que se estenderam durante as relações com os países europeus. A religião islâmica sempre foi um ponto de receio para os colonizadores, pois ela continha características que poderiam fomentar uma sublevação sistemática das populações africanas da região, servindo como um ponto de união com possibilidades de contestar a hegemonia dos europeus (OPOKU, 2010). O medo dos franceses se intensifica em razão da rápida expansão da confraria Mouride. Isso se deve ao contexto de hostilidade da ocupação estrangeira, que torna o grupo religioso bastante atrativo para as populações locais. A confraria possuía uma organização móvel, baseada nas chamadas dahiras, pequenos grupos com reuniões periódicas de reza e discussão de problemas, com a referência de um líder espiritual constante e mi- 
grante. Esses fatores, aliados a um discurso baseado no trabalho, na obediência e na cooperação, auxiliaram na rápida expansão do número de participantes, e, também, chamou a atenção das autoridades imperialistas, que não viram com bons olhos o surgimento de um grupo coeso no centro produtor de amendoim, em partícular, na região do Bassin Arachidier.

O Islã, também era favorecido pelas tecnologias de comunicação e transporte trazidas pelos europeus, possibilitando sua expansão em áreas antes inacessíveis. A postura francesa, orientada pela necessidade de impor a cultura europeia às populações de suas colônias, para "elevar o nível da população colonizada oferecendo a ela os 'benefícios' da cultura francesa" (DIOP et al., 2010, p. 29), acarretava em uma postura de maior hostilidade dos franceses em relação aos grupos muçulmanos, limitando sua área de influência as regiões em que já se encontravam, algumas vezes reforçando a religião tradicional e legitimando um direito consuetudinário dessas populações (GUEYE; BOAHEN, 2010).

Como já falamos, a guerra servira como potencializadora de atitudes que estavam latentes nas populações. Em 1944, o regime fascista de Vichy foi expulso das colônias, e, com isso, iniciou-se o processo de reestruturação e organização de uma política pós-guerra. A degradação da situação internacional da França, acarretada pela sua postura de restauração colonial, a partir de 1947, com a repressão a movimentos de independência em todas as suas possessões, agravou também a situação das colônias da África Ocidental. A independência política do Senegal ${ }^{3}$ se efetiva em 1960 após grandes embates políticos e organizações sociais da sociedade civil no país e nos vizinhos, em particular, no Mali e na Costa do Avorio (LALOU, 1996).

\footnotetext{
${ }^{3}$ Não é nosso objetivo analisar os processos que produziram a independência política do Senegal, porém, é interessante enfatizar que a ação desse país foi fundamental para desencadear grande parte das independências da África Ocidental. Lideranças políticas souberam costurar acordos com os países vizinhos, viabilizar conferências entre si em torno do tema, bem como permitir a permanência de empresas e empreendimentos franceses no interior do país. As organizações políticas do país desenvolveram muito as noções de negritude e de pan-africanismo. Nesse sentido, obtiveram unidade nacional. A criação da Federação do Mali, em 1959, perpassou um conjunto de reuniões de organização e planejamento, e, apesar do consenso sobre o caráter positivo de uma união política, existia uma divergência quanto à forma e à postura do conjunto, principalmente em relação à França. Em termos de orientação econômica, foi escolhida a perspectiva liberal, mantendo-se a moeda Franco CFA, em alinhamento às ideias prescritas pela metrópole. Evidenciou-se que o processo de independência tendeu a ser uma organização que, em nome de ideais nacionalistas de uma identidade senegalesa, serviu, pela característica de continuidade de políticas, para a ascensão de grupos que formariam uma nova elite dirigente (DIALLO, 2011; BOAHEN, 2010).
} 


\section{A agricultura e o processo migratório}

Para sanar a crise econômica e social, além da abertura política, foram colocados em ação programas de estabilização financeira, orientados por órgãos financeiros internacionais como o Banco Mundial e o Fundo Monetário Internacional. Nesse sentido, a década de 1960 demonstra o intenso processo de modernização da agricultura expresso em técnicas advindas de fora (França e Estados Unidos), uso de agroquímicos e de máquinas agrícolas. Tornava-se visível que a independência política não significava independência econômica (FREUD; RICHARD; THÉNEVIN, 2011). A cultura do amendoim na região do Bassin Arachidier passava por um intenso processo de alteração produtiva. Unidades familiares de produção foram pressionadas a abandonar outras culturas e se dedicar à monocultura do amendoim. Sob a orientação de agências de fomento da França, aliadas aos bancos internacionais, bem como às agroindústrias, algumas regiões do Senegal foram pressionadas à especialização produtiva.

Figura 2: Cultura do amendoim na região do Bassin Arachidier, centrooeste do Senegal

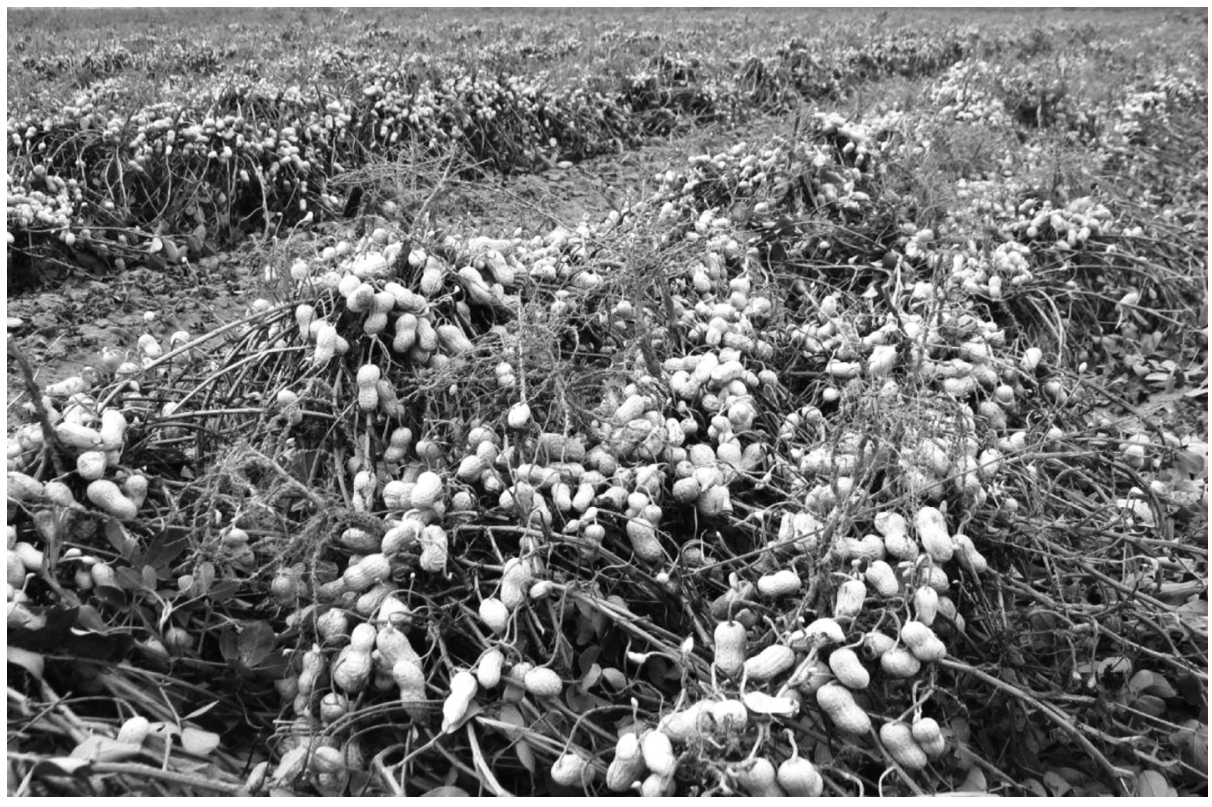

Fonte: Partenariat pour les Forêts du Bassin du Congo. 2017. Disponível em: <http://pfbccbfp.org/actualites/items/IITA-Aflasafe.html>. Acesso em: 16 abr. 2017. 
O caso da cultura do amendoim, que, na realidade, foi inserida pelos franceses na segunda metade do século XIX, ganha agora, principalmente na grande região do Bassin Arachidier, um performance de cultura de exportação. Muitos pequenos agricultores não tiveram condições de acompanhar as novas exigências (variedades, técnicas produtivas, aquisição de máquinas, dependência em relação às agroindústrias de óleo do amendoim, níveis de produtividade regulando os preços, determinações externas desses, etc.) e foram obrigados a migrar para centros urbanos de regiões como Kaolack, Thiès, Diourbel e Dakar.

A região do Bassin Arachidier, que tem como referência os municípios de Dourbel, Sine-Saloum e Thiès, situa-se na planície do centro-oeste do Senegal e que vai ao sul até Gâmbia. É centenária na produção de amendoim, mas, também, como expressão das transformações do meio rural. Isso tudo foi favorecido também pela estrada de ferro que corta a região e a liga com Dakar.

Na década de 1970, 60\% da população rural do país estava localizada nessa região; nos anos 2000, não passou de $26 \%$. A superfície média das unidades familiares no ano 2000 era de 4,68 ha. Com a especialização da monocultura do amendoim, grande parte da receita financeira que o produto promovia nas unidades familiares produtivas servia para comprar outros cereais (arroz, milho, sorgo). Pesquisas feitas nessa região indicam que, no ano 2000 , em torno de $20 \%$ das famílias possuíam um membro imigrante (DIOP, 2008, p. 89).

A década de 1990 representou um conjuntural aumento dos níveis de pobreza, tributário também da desvalorização do Franco CFA, que sofreu uma queda de $50 \%$ em relação ao Franco francês, encarecendo as importações. Em outro viés, a produção agrícola padeceu com a contínua degradação das áreas agricultáveis. Nas regiões costeiras, o processo de salinização acabou por reduzir terras produtivas que, paulatinamente, diminuiu a produtividade, isso tudo somado ao assoreamento de rios e as secas.

Nas últimas décadas, a participação do setor primário na economia passou por uma redução considerável: de mais de $26 \%$ do PIB na década de 1970, para 16\% nos anos 2000 (HERRERA; QUINTANA; ALONSO, 2010). Esse contexto fomentou a migração interna, via êxodo rural e intracidades para os centros urbanos maiores, principalmente o da capital, Dakar. A cidade concentra hoje quase $30 \%$ da população do país. 
A agricultura do país sofre com as consequências dos processos de monocultura regional, com a falta de recursos de fomento ao desenvolvimento e alternativas produtivas, com o fato de que, em determinadas regiões, as unidades familiares possuem seus chefes com idade avançada, a juventude migra para as grandes cidades ou para outros países. Em torno de $60 \%$ dos cereais consumidos no país (arroz, em particular) são importados. Em 2015, o país importou três vezes mais do que exportou, com isso há grande déficit comercial, o qual é compensado, em grande parte, pelas remessas dos imigrantes que, em 2015, contribuiu com $17 \%$ do PIB do país. A taxa de desemprego em 2016 atingiu a marca dos 50\% dos trabalhadores (PEA), e o emprego informal absorvia mais de 70\% da força de trabalho (CEPED, 2017).

\section{As múltiplas dimensões da emigração}

No período colonial, a emigração deu-se como forma de resistência e/ou de pressão do agente colonizador para espaços de seu interesse geopolítico e econômico; no período pós-independência, ela esteve relacionada à crônica falta de oportunidades que o país apresentava. Os países vizinhos, ou próximos, em situações favoráveis, necessitando de mão de obra, passaram a ser, primeiramente, os destinos naturais para esse contingente da população desprovido de meios de produção e de renda. Os efeitos das transformações climáticas afetam economicamente, principalmente as regiões rurais, em processos de redução das áreas cultiváveis.

No final da década de 1990, as políticas de subsídio americano à produção e ao comércio do óleo do girassol e da canola contribuíram para a crise do amendoim no Senegal, pois rivalizaram os óleos de cozinha. Nesse sentido, a emigração para a Europa e os Estados Unidos foi uma consequência também desse processo, assim como o foi em relação ao algodão que formava a base econômica de vários países africanos e sofreu uma grande crise em razão de políticas de preços subsidiados (dumping) pelo governo americano ao seu produto no mercado externo, fazendo com que a produção africana perdesse grande parte dos espaços (SOME, 2009). Outro fator conjuntural que fez aumentar a emigração do país, como já falamos, foi a desvalorização do franco CFA (moeda do Senegal) que houve em 1994, a qual reduziu pela metade o poder de compra nas antigas colônias francesas, cujas moedas tinham no franco francês sua correlação monetária. Isso fez com que a emigração se intensificasse por duas razões: uma pela perda 
do poder de compra e outra pela possibilidade de ganhar em francos franceses que, em tempo curto, acabaram valendo o dobro do que o CFA, e que permitiu um câmbio vantajoso aos emigrantes e a sua gente no Senegal através de remessas externas.

Desse modo, muitos países da África tiveram compensações financeiras pelas remessas de emigrantes. Em razão disso, passou a ser um bom negócio mandar gente para outros países, em particular, para a Europa e os Estados Unidos. Estima-se que quase 3 milhões de senegaleses estão espalhados pelo mundo, especialmente, pela Europa (França, Itália e Espanha como centrais), sobre uma população de um pouco mais ou menos de 14 milhões. Em 2015, as remessas dos emigrantes atingiram 17\% do PIB do país (em torno de U\$ 2 bilhões); segundo analistas, isso provoca uma grande dependência do país em relação ao dinheiro enviado pelos imigrantes e, também, não necessariamente promove o desenvolvimento interno, ou seu uso produtivo, em razão de que não é investido em setores que mais necessitam e que sejam germinadores de uma melhor qualidade de vida para a população em geral. Pesquisadores do país enfatizam que há cidades em que em torno de $80 \%$ da população depende desse dinheiro externo (FALL, 2010; NDIAYE, 2011).

A emigração é vista como uma estratégia, uma ação racionalizadora em termos econômicos e sociais, familiares e religiosos; ela orienta práticas, aspirações familiares de mobilidade e status social (SAKHO; DIOP; AWISSI-SALL, 2011). Em geral, até bem pouco tempo, eram os homens que emigravam, porém, as mulheres já estão em grande dinamismo. A migração e a emigração de mulheres senegalesas intensificou-se na década de 1990 e provocou profundas transformações na família, nas relações de gênero, pois as mulheres eram apreciadas no contexto da vida familiar. As mulheres imigrantes passaram a contribuir de uma forma mais intensa na economia familiar. Os estudos mais recentes indicam que nas maiores cidades, dentre elas, Dakar, a proporção que era de sete homens para três mulheres em 1990, passou de três homens para duas mulheres em 2014 (SAKHO; DIAL, 2014). Ambos buscam, pela emigração, promover status social ao grupo familiar, responsabilidade moral de ambos os cônjuges em redistribuir seus ganhos no interior do grupo (GOLDBERG, 2003). "A migração é muitas vezes interpretada, à imagem da circuncisão, como um rito de passagem, um marco importante no curriculum individual. Seria preciso partir para ser homem, ter um status social ou reconhecimento" (FALL, 2010, p. 2). 
Os filhos emigrantes são a esperança da família; a mulher é valorizada na família pelo sucesso de seu filho; desse modo, mães tentam constituir redes e vínculos para viabilizar a emigração de filhos. "A concorrência entre coesposas leva a mãe a financiar o projeto migratório de seu filho através de suas economias" (SHAKO; DIOP; MBOUP; DIADIOU, 2015, p. 42). Redes familiares, de parentela, de corregionalidade, de agrupamento religioso, de amizades e de interconhecimento, vão produzindo processos migratórios. Essas redes demonstram que os imigrantes são também sujeitos ativos, capazes de produzir estratégias, adaptação em contextos e rede de relações. As redes facilitam saídas e chegadas, gestão da documentação, emprego, comunicação, trocas econômicas e sociais. Elas fazem com que os emigrantes possam manter a unidade familiar e parental ligada com a comunidade de origem (AMBROSINI, 2008).

Estudos revelam certas especificidades de destinos em correspondência com a origem dos fluxos, ou seja, os do Vale do Rio Senegal dirigiramse para a França e aos vizinhos do Senegal, os do Bassin Arachidier, em grande crise agrícola, emigraram para o sul da Europa (Itália, Espanha e Portugal), os da região de Dakar dirigiram-se para o norte da Europa e para os Estados Unidos. Estudos recentes informam que há uma "fuga de cérebros"; ou seja, os emigrantes possuem, em grande parte, um nível elevado de estudos; $54,2 \%$ dos emigrantes, em 2014, possuíam ensino superior (SHAKO; DIOP; MBOUP; DIADIOU, 2015).

\section{Dinâmicas econômicas e socioambientais}

Em termos de causalidades estruturais na atualidade no Senegal, como já vimos, estudos demonstram a intensificação da erosão costeira e a salinização dos solos, a baixa atividade da pesca, fruto da destruição da infraestrutura e da alta pesca industrial, a renda decrescente dos produtos agrícolas, o desaparecimento de cobertura vegetal, que expõe o solo a um processo maior de erosão. As secas e a baixa rentabilidade da produção do amendoim também são alguns dos processos internos que fazem com que muitos pequenos agricultores ou toda a família migrem temporariamente para cidades maiores (THIAM; CROWLEY, 2014; NDIONE, 2012).

É necessário também compreender os vínculos coloniais das primeiras décadas do século XX e as duas grandes guerras, a relação do país com os seus vizinhos colonizados pela França, as condições de produção na 
região do Vale do Rio Senegal, no norte do país e as transformações da agricultura para a criação de gado, as profundas transformações agrícolas da imensa região do Bassin Arachidier, a centralidade da produção do amendoim e a emigração rural-urbana que esse cenário produziu, principalmente para as cidades de Dakar, Thiès e Kalaouka; nesse cenário está o fenômeno da globalização e a sua consequente metropolização (centralidade econômica das grandes cidades) e internacionalização (da informação, dos contatos e do mundo mercantil).

Vimos que no caso do Senegal as primeiras migrações pós-independência davam-se entre países vizinhos (zona da África Ocidental - Costa do Marfim, Mali, Mauritânia, Cabo Verde, Nigéria) e na dimensão sazonal. Nas décadas de 1970 e 80, a representação de que a riqueza deveria ser buscada na Europa (França, Espanha, Itália, Inglaterra) produziu grandes levas de emigrantes; após final da década de 1990, com as restrições da França e outros países da Europa, os canais da América do Norte apresentaram-se como alternativa. Em 1999, havia em torno de 400 mil senegaleses emigrados; em 2016, calcula-se em torno de três milhões. A partir do início do século XXI, outros destinos foram se constituindo, entre eles, o Brasil (CEPED, 2017).

A possibilidade de emigrar faz com que também seja reduzida a prole familiar dos que ficam, pois há fragmentação da família pela emigração de um dos cônjuges, em geral, o marido/pai; além de que emigrantes nos locais de destino geram menos filhos do que se estivessem no espaço original. Estudos sobre imigração na Europa enfatizam que essa realidade acaba indo na contracorrente do que se espera dos imigrantes. Países como Itália, Alemanha e França contam com os imigrantes no crescimento demográfico do país, porém, isso não acontece com normalidade, pois os imigrantes têm dificuldade em produzir filhos fora de seu local de origem em razão do aumento dos custos de moradia e de sobrevivência, da redução do tempo de trabalho, em geral da mulher/mãe, da ausência de políticas sociais mais efetivas para eles.

Em correspondência com esses processos, redefinem-se inúmeras questões de ordem econômica, territorial e de papéis de gênero na família. A emigração passa a ser uma estratégia para permitir o equilíbrio entre a população e as possibilidades do meio em fazer face às dificuldades socioeconômicas. Ela exerce um amplo processo de mudança nas microrrelações familiares, sociais, culturais, além de ser um grande recurso econômico, demográfico e religioso (GAMBERONI; PISTOCCHI, 2013). 
Frente a isso tudo, é necessário perceber processos estruturais e estratégias dos sujeitos/grupos sociais na questão da mobilidade geográfica (JASON; SCHACHTER, 2008). Há, sem dúvida, além dessa questão da família, uma estreita correlação entre economia e imigração. Já é lugar comum nas análises sobre imigração que os sujeitos que emigram melhoram o contexto socioeconômico do cenário de origem através dos fluxos de remessas, pela modernização social e tecnológica (consumo e atividades produtivas, acesso à educação dos filhos, etc.) (BLANCHARA, 2002); nesse sentido, há um ativismo dos imigrantes na dimensão transnacional e o melhoramento das condições de vida no cenário familiar e comunitário de origem.

A mudança ambiental agrava a pobreza e a segurança alimentar, aumentando o desemprego entre jovens, colaborando ainda mais para destruir o frágil equilíbrio econômico doméstico, e a vulnerabilidade das famílias aumenta, das mulheres, em particular. Isso explica o aumento das (e)migrações femininas. As mulheres revelam o contexto de uma sociedade pós-fordista, baseada na emigração dos serviços, na flexibilização no mercado de trabalho; seu papel também é importante na esfera da reprodução fisica e simbólica da família, com suas responsabilidades e deveres (BEAUCHEMIN et al., 2013).

Em 2011 houve a maior seca dos últimos 60 anos no Senegal. Em torno de $30 \%$ da população rural passou a ser migrante sazonal, principalmente no período de seca. Em 2012, em torno de $43 \%$ da população (cinco a seis milhões) residia no meio rural; boa parte dessa população, não encontrando mais trabalho nas grandes cidades, torna-se um viveiro de emigrantes e, nesse contexto, as mulheres se inserem também (CEPED, 2017). Desse modo, processos econômicos, políticos e demográficos se juntam aos ambientais para produzir uma estrutura de causalidades das emigrações e redefinindo trajetórias até então bastante precisas entre os gêneros na família.

A forte inserção do grupo imigrante senegalês ao horizonte religioso advém também dessa história de situações-limite de vida; o associacionismo (confrarias) religioso e comunitário, revela a necessidade em manterem-se unidos, vinculados e desenvolvendo ações de cunho solidário, como forma de gerenciar as relações com os novos contextos, objetivos e funções (CESCHI; STOCCHIERO, 2006).

Os emigrantes, em geral, invocam a fidelidade às tradições no país de origem; suas esposas, em geral, permanecem com os pais (sogro/sogra) e ocupam-se com os filhos. Com isso, desenvolvem-se processos de auto e 
altervigilância, bem como de auxílio mútuo em meio à constituição do núcleo familiar. Há uma grande ausência dos pais na educação dos filhos (muitos filhos viverão muito tempo sem a presença física dos pais), processo esse que delega, em grande parte às mães que permanecem e/ou aos avós o cuidado dos filhos, ainda que se deva entender a importância da família ampliada (parentesco, compadrio e toda a estrutura normativa poligâmica) (DAGUERRE, 2010). Os emigrantes também necessitam lançar mão de coletividades para auxiliar no processo de educação e criação de filhos. Porém, a dimensão de transmigrante (está aqui e está lá ao mesmo tempo), facilitada pelas redes de informação e contato, ameniza um pouco essa dimensão limitada do face a face. Possibilidades de retorno ao local de origem podem acontecer com mais facilidade hoje do que em relação à velha emigração.

Para Sayad (2008), o sujeito imigrante não é do lugar de destino, de seu pertencimento e vínculo; ele está num outro ambiente. Diz o autor que o desejo de retornar significa um reclamo às origens, à condição inicial, àquela de emigrante antes de imigrante; é algo que está no âmago da condição de imigrante, que implica uma concepção de tempo em que o futuro é redirecionado como se fosse um retorno a si mesmo, ao seu grupo, ou seja, uma retrospectiva pessoal. O retorno também passa a ser idealizado, programado, desejado e viabilizado. Porém, ao retornar, imigrantes têm dificuldade de permanecer por muito tempo, replanejam suas vidas tendo a identidade de emigrante novamente como possibilidade. Desse modo, a emigração, a identidade de imigrante, de retornado e de re-emigrante revela múltiplos dinamismos, movimentos e alterações que se processam na alteração dos territórios e nas condições da vida cotidiana e dos sujeitos que se distanciam e se aproximam; são realidades complexas, não definidas a priori e que operam mudanças subjetivas, valorativas e nas idealizações.

\section{Considerações finais}

Com o processo da globalização econômica e informacional, com o aprofundamento da divisão internacional do trabalho (em que países empobrecidos continuam sendo espaço de trabalho, consumo e oferta de matérias-primas) e do já consolidado mapa mundi da riqueza e da pobreza, as migrações laborais começam a intensificar-se com novas fronteiras e novos espaços. A mobilidade geográfica, para os senegaleses, constitui-se como 
um modo de vida. Faz parte de múltiplas estratégias racionalizadas e decididas no interior da família e provocadas por situações-limite vividas no interior do país (TALL, 2002), na idealização de projeção social de quem emigra e da maior garantia de sobrevivência da família (DIAL; SHAKO, 2010).

É possível indicar alguns fatores mais estruturantes que, em países empobrecidos, não só da África, mas em particular, estão nas raízes de muitas das decisões de emigrar. Dentre elas, o passado colonial (em geral, com países da Europa Ocidental) e o desenvolvimento econômico póscolonial, os macro-programas de ajuste econômico impressos de fora por instâncias econômicas e geopolíticas de cunho neoliberal (SOME, 2009; COUSSY; VALLIN, 1996); programas esses, em geral, sob a falácia da necessidade de "ajustes estruturais", de profunda redução do Estado na economia, os quais imprimem disciplina fiscal, no gasto público, privatizações, flexibilização dos regramentos e garantias no trabalho, agricultura para exportação (por isso a modernização aliada à especialização produtiva), dentre vários outros aspectos (KLEIDERMACHER, 2013).

A emigração de senegaleses, ainda que seja de indivíduos, ou seja, assumida por um ou mais membros da família (em geral, masculinos), envolve o coletivo e a estrutura familiar. A saída de algum membro não significa que o núcleo familiar se fragmenta; ao contrário, fortalece-se, pois a mobilidade de alguns, implica aglutinar outros envolvidos no processo, tais como a família do/da cônjuge, amigos e parentes. O emigrante passa a ser visto como alguém com probabilidade de êxito, de referência social, que incorpora, no horizonte distante, as obrigações familiares, sociais e morais de distribuição de seus ganhos, auxiliando a família (MA GASSOUBA, 1966). Nesse sentido, o trabalho dota o indivíduo de liberdade de ação, de filiação e paternidade divina, energia social à comunidade e da comunidade para a humanidade; é uma prova de sacrifício e de humanização. O homem peregrino é um ser para o trabalho (por isso, a emigração) (KAAG, 2006; GUICHAOUA, 2004; TARRIUS, 1989).

O sacrifício em fazer poupança em outro país é sinônimo de possibilidade de investir no local de origem. Essa lógica entre parcimônia em um local e investimento no outro é lugar comum em meio aos emigrantes senegaleses; eles não investem nos espaços de destino. Esse processo auxilia na vida distante, permite sobreviver a situações adversas (LAHLOU, 2004). Dessa forma, o envio de remessas é entendido como legítimo e compensador não só para a unidade familiar do esposo/esposa, mas para a família 
ampliada que pode ser os avós/sogros e, em alguns casos, até parentes. São campos sociais e trocas culturais transnacionais (SASSEN, 2008; AMBROSINI, 2008) constituídos entre quem ficou e quem partiu em que o dinheiro produz a colagem.

A emigração revela um amplo tecido de causalidades, consequências e dimensões sociais. É um fato totalizante da história da humanidade. No caso específico da emigração senegalesa para várias partes do mundo, entre elas, para a América do Sul, não dá para entendê-la sem ter presente as transformações na agricultura, as questões ambientais que assolam vários países da África Ocidental, as consequências da colonização, a fragilidade do Estado em oportunizar renda e emprego à população, bem como processos que se redefinem em horizontes culturais, religiosos e familiares. As múltiplas estratégias de fluxos de que os emigrantes lançam mão devem também ser vistas sob a ótica das oportunidades, das descobertas e atrações. Fechamentos de espaços podem significar aberturas em outros. Nesse sentido, os emigrantes revelam ser sujeitos ativos do mundo contemporâneo, ao mesmo tempo em que são vítimas de múltiplas mudanças ambientais, culturais e religiosas.

Enfim, esse mundo em movimento, produzido pelos emigrantes, vem ocasionando muitos conflitos e tensões sociais, redefinindo fronteiras nacionais, políticas de fechamento, legislações restritivas, mortes nos mares e nos muros que dividem países. Os emigrantes desafiam pressupostos da globalização, demonstram a fragilidade dos estados nacionais, bem como a debilidade e, ao mesmo tempo, a resistência de ações integrativas e de acolhida. O mundo do trabalho os acolhe, mas a sociedade, de uma forma geral, não os quer. São tratados ainda como ameaça e com temor. Não há um amplo espectro de políticas e de ações econômicas que tentam resolver a questão pelas suas causas. Fazer isso é também reconhecer a histórica colonização/neo-colonização e suas consequências econômicas, o imperialismo comercial e tecnológico de países centrais do mundo econômico, a pilhagem das riquezas naturais e as políticas que impedem o desenvolvimento autônomo de países de origem dos fluxos. Por isso, não se desenham grandes alternativas e nem alteração no intenso processo em curso, fato esse que colocará ainda a emigração e o emigrante no centro dos grandes debates e embates sociais na contemporaneidade. 
TEDESCO, J. C. • A imigração senegalesa: dimensões históricas, econômicas e socioambientais

\section{Referências}

AMBROSINI, M. Un'altra globalizzazione. La sfida delle migrazioni transnazionali. Bologna: Il Mulino, 2008.

BADIER. B. Pour une autre regard sur les migrations: construire une gouvernance mondiale. Paris: La Découverte, 2008.

BEAUCHEMIN, et al. Migrations africaines: le codéveloppement em question. Paris: Armand Collin, 2013.

BLANCHARA, M. Donne senegalese in Italia. Migranti Muridi tra iniziativa femminile e controlo dela confraternita. In: COLOMBO, A.; SCIORTINO, G. (a cura di). Stranieri in Italia. Assimilati ed esclusi. Bologna: Il Mulino, p. 91-118, 2002, p. 147-234.

BOAHEM, Albert Adu. A África diante do desafio colonial. In:BOAHEM, Albert Adu (Org.). História geral da África: África sob dominação colonial, 1880-1935. Brasília: UNESCO, 2010, v. VII, p. 1-20.

BOAHEN, Albert Adu. Política e nacionalismo na África ocidental, 1919-1935 In: BOAHEN, Albert Adu (Org.). História geral da África: África sob dominação colonial, 1880-1935. Brasília: UNESCO, 2010, v. VII, p. 727-756.

CEPED (Centre Population et Developpement). West African from explosion to proliferation. 2017. Document.

CESCHI S.; STOCCHIERO A. (A cura di). Relazioni transnazionali e co-sviluppo. Associazioni e imprenditori senegalesi tra Italia e luoghi di origine. Torino: Harmattan Italia, 2006.

COQUERY-VIDROVITCH, C. A economia colonial das antigas zonas francesas, belgas e portuguesas (1914-1935). In: BOAHEN, Albert Adu (Org.). História geral da África: África sob dominação colonial, 1880-1935. Brasília: UNESCO, 2010, v. VII, p. 401-436.

COUSSY, J.; VALLIN, J. (Eds.). Crise et population en Afrique: crises économiques, politiques d'ajustement et dynamiques démographiques. Paris: Les Études de CEPED, n. 13, 1996.

DAGUERRE, V. L'immigration: problématiques et défis. Paris: Éditions du Cygne, 2010.

DIAL, F. B.; SAKHO, P. Migration clandestine féminine: Etude de cas de Dakar et sa banlieu. In: CARIM. Notes d'analyse et de Synthèse, n. 56, 2010.

DIALLO, M. A construção do Estado no Senegal e a integração na África Ocidental: Os problemas da Gâmbia, Casamance e da integração regional. Dissertação (Mestrado em História), Porto Alegre: UFRGS, 2011. 
DIOP, M. C. (Ed.). La Société sénégalaise entre le local et le global. Paris: Karthala, 2002.

DIOP, M. C. (Ed.). Le Sénégal des migrations: mobilités, identités, et sociétés. Paris: Karthala, 2008.

DIOP, Majhemout et al. A África tropical e a África equatorial sob domínio francês, espanhol e português. In: MAZRUI, Ali A.; WONDJI, Christophe. (Orgs.). História geral da África: África desde 1935. Brasília: UNESCO, 2010, v. VIII, p. 67-88.

FALL, P. D. Sénégal. Migrations, marché du travail et développement. Ginevra: INES, 2010.

FREUD, C.; RICHARD, J.; THÉNEVIN, P. L'arachide au Sénégal: um moteur em panne. Paris: Karthala, 2011.

GAMBERONI, E.; PISTOCCHI, F. L'Africa Occidentale: ritrato di un'Africa che cambia. Bologna: Pátron-Editore, 2013.

GOLDBERG, A. Ser inmigrante no es una enfermedad. Inmigración, condiciones de vida y de trabajo. El proceso de salud/enfermedad/atención de los inmigrantes senegaleses en Barcelona. Tesis de Maestría. Universitat Rovira i Virgili, 2003.

GUICHAOUA, Y. L'analise microéconomique des relations d'emploi dans le secteur informal urbain. Une étude de cas en Côte d'Ivoire. Paris: EHSS, 2004. Thèse de Doctorat en Sciences Economiques.

GUEYE, M.; BOAHEN, A. Iniciativas e resistência africanas na África ocidental, 1880-1914. In: BOAHEN, A. (Org.). História geral da África: África sob dominação colonial, 1880-1935. Brasília: UNESCO, 2010, v. VII, p. 129-166.

HERRERA, G.; CARILLO, M. C. Trasformazioni familiari nel'esperienza migratoria ecuadoriana. Uno sguardo dal contexto di partenza. Rivista Mondi Migranti, n. 3. Milano, p. 63-83, 2010.

JASON, P.; SCHACHTER, R. Amélioration des données sur la migration en Afrique de l'Ouest et centrale. Utilisation des Enquêtes auprès des Ménages pour l'evaluation de la migration passée, présente et future en Afrique de l'Ouest et du centre. OIM, Genève, Juillet, 2008. Documento da OIM.

KAAG, M. Il ruolo dela confraternita dei Muiridi nella vita dei migrante senegalesi. In: PALTRINIERI, A. C. (a cura di). Un futuro in gioco. Tra muridi senegalesi e comunità italiana. Milano: Franco Angeli, 2006, p. 125-131.

KLEIDERMACHER, G. Entre confrarias y venta ambulante: una caracterización de la inmigración senegalesa en Buenos Aires. In: Cuadernos de Antropología Social, n. 38. Buenos Aires: UBA, p. 109-130, 2013.

KLEIDERMACHER, G. Movilidad e insercíon de inmigrantes senegaleses recientes en la Ciudad Autónoma de Buenos Aires. Revista Internacional de Estudios Migratorios (RIEM). V. 5 (1), p. 93-118, 2015. 
LAHLOU, M. Filières migratoires subsahariennes vers l'Europe (via le Maghreb)." In: MARFAING, L.; WIPPEL, S. (Eds.). Les Relations transsahariennes à l'époque contemporaine: un espace en constante mutation. Paris: St. Éditions, 2004, p. 113140.

LALOU, R. Les migrations internationales en Afrique de 1'Ouest face à la crise. In: COUSSY, J.; VALLIN, J. (Eds.). Crise et population en Afrique. Paris: CEPED, 1996, p. 346-373.

MA GASSOUBA, M. L'Islam au Sénégal. Paris: Karthala, 1966.

MALOMANO, B.; FONSECA, D. J.; BADI, M. K. Diáspora africana e migração na era da globalização: experiências de refúgio, estudo, trabalho. Curitiba: CRV, 2015.

NDIAYE, E. M. L'economie Sénégalaise: enjeux et problématiques. Dakar: L'Harmattan-Sénégal, 2011.

NDIONE, B. (Ed.). Les Statistiques des travailleurs migrants en Afrique de l'Ouest: Synthèse sous-regionale. Projet: Migration de main-d'oeuvre pour l'integration et le developpement en Afrique, Dakar: ILO, 2012.

OPOKU, K. A. A religião na África durante a época colonial. In: BOAHEN, A. (Org.). História geral da África: África sob dominação colonial, 1880-1935. Brasília: UNESCO, 2010, v. VII, p. 591-624.

POIRET, C. Familles africaines em France. Paris: L'Harmattan, 1996.

SAKHO, P.; DIAL, F. B. Cadre general des migrations sénégalaises. In: Notes d'analyse et de Synthèse. Module Démographique et Économique, n. 73. Florence, p. 2346, 2014.

SAKHO, P.; DIOP, R.; AWISSI-SALL, M. Migration et genre au Sénégal. Florence: EUI, 2011.

SAKO, P. S. Senegal: storia, economia e risorse. Bologna: L'Arca, 1998.

SASSEN, S. Una sociologia della globalizzazione. Torino: Einaudi, 2008.

SAYAD, A. L'immigrazione o i paradossi dell'alterità. L'illusione del provvisorio. Verona: Ombre Corte, 2008.

SHAKO, P.; DIOP, R. A.; MBOUP, B.; DIADIOU, D. A emigração internacional senegalesa: das casas no campo às cidades litorâneas. In: HEREDIA, V. B. M. (Org.). Migrações internacionais: o caso dos senegaleses no sul do Brasil. Caxias do Sul: Quatrilho Editorial, 2015, p. 23-50.

SOME, A. N. Migration internationale au Sénegal: profil national pour le développement de politques stratégiques. Dakar: OIM, 2009.

TALL, S. M. Investir dans le ville africaine: les émigrés et 1'habitat à Dakar. Paris: Karthala, 2009. 
TALL, S. M. L'Émigration internationale sénégalaise d'hier à demain. In: DIOP, M. C. (Ed.). La Société sénégalaise entre le local et le global. Paris: Kathala, 2002, p. 549578.

TARRIUS, A. Anthropologie du mouvement. Paris: Paradigmes, 1989.

TEDESCO, J. C.; MELLO, P. A. Senegaleses no centro-norte do Rio Grande do Sul: imigração laboral e dinâmica social. Porto Alegre: Letra \& Vida, 2015.

THIAM, M. T.; CROWLEY, J. Impact des changements environnementaux sur les migrations humane. Études de cas: Sénégal et Côte d'Ivoire. Unesco: Jerin, 2014.

WIHTOL DE WENDEN, C. Atlas des migrations dans le monde. Paris: Altrement, 2005.

WIHTOL DE WENDEN, C. La question migratoire au XXIe siècle. Paris: Presses de Sciences Po, 2013. 